\title{
Structural Properties and Electrical Conductivity of Copper Substituted Nickel Nano Ferrites
}

\author{
K. Vijaya Kumar, Rapolu Sridhar, D. Ravinder, and K. Rama Krishna
}

\begin{abstract}
A series of copper substituted nickel nano ferrites with the compositional formula $\mathrm{Ni}_{1-}{ }_{-} \mathrm{Cu}_{X} \mathrm{Fe}_{2} \mathrm{O}_{4}(X=0,0.2,0.4$, 0.5, 0.6, 0.8 and 1.0) were prepared by the Citrate gel auto combustion technique and sintered at $700^{\circ} \mathrm{C}$ for $5 \mathrm{hr}$. The X-ray difractrograms (XRD) clearly exhibited the existence of single phase cubic spinel structure. The crystallite size was found in the range of $36-58 \mathrm{~nm}$. With the increment of $\mathrm{Cu}$ content the $\mathrm{X}$-ray density and porosity were found to increase where as the bulk density was found to decrease. The DC electrical properties were carried out by two-probe method from room temperature to well beyond the Curie temperature. DC electrical resistivity decreases with increase of temperature ensuring the semiconducting nature of the ferrites. The DC electrical conductivity found to increase with increase of $\mathrm{Cu}$ content and reaches maximum at $X=1.0$ at which the activation energy for conduction becomes minimum. The activation energy in the ferrimagnetic region is in general lesser than that in the paramagnetic region. The activation energy was found to decrease with the increase of $\mathrm{Cu}$ content. The Curie temperature determined from DC electrical properties was found in satisfactory agreement with that determined from Loria technique. The DC electrical resistivity results are discussed in terms of hopping model.
\end{abstract}

Index Terms - Ni-Cu nano ferrite, x-ray density, bulk density, porosity, DC electrical properties.

\section{INTRODUCTION}

Spinel ferrites have been studied extensively due to easy to synthesis and abundant uses in technological and industrial applications [1]-[3]. The useful properties of the spinel ferrites mostly depend upon the chemical composition, preparation methods, sintering temperature, nature of the additives and their distribution i.e. tendency to occupy tetrahedral (A) or octahedral (B) site [4]. $\mathrm{Ni}^{2+}$ has a strong preference octahedral site (B-site) for the electrical conductivity [5]. $\mathrm{Cu}^{2+}$ is the divalent ions which occupy essentially tetrahedral A-site depending on the sample preparation [6] when substituted in ferrites.

Among the spinel structures, nickel ferrite have been widely used in different kinds of magnetic devices, such as

Manuscript received November 3, 2013; revised January 16, 2014.

K. Vijaya Kumar is with Department of Physics, JNTU Hyderabad College of Engineering, Nachupally (Kondagattu), Karimnagar-505501, Andhra Pradesh, India (e-mail: kvkphd@gmail.com).

Rapolu Sridhar is with Vignan's Institute of Technology \& Aeronautical Engineering College, Deshmukhi, Nalgonda-508284, Andhra Pradesh, India (e-mail: rapolu31@gmail.com).

D. Ravinder is with Department of Physics, Nizam College, Bashbeerbagh, Osmania University, Hyderabad- 500001, Andhra Pradesh, India(e-mail: ravindergupta28@rediffmail.com).

K. Rama Krishna is with Department of Physics, Malla Reddy College of Engineering \& Technology, Secunderabad, India (e-mail: ramu521@yahoo.com). inductors, magnetic heads, and magnetic devices, such as inductors, magnetic heads, magnetic refrigeration and magnetic resonance imaging. Thus, the magnetic and electric properties of nickel ferrite have been researched and improved. $\mathrm{Cu}$-containing ferrites form an interesting group of ferrites because of their typical electrical and magnetic properties and change in crystal structure on thermal treatment [7].

$\mathrm{Ni}-\mathrm{Cu}$ ferrites are low cost materials and have important magnetic and electrical properties for technological applications. The electrical conductivity of spinel ferrites is of prime importance as it gives valuable information about the conduction mechanism [8]. Therefore a systematic study of the electrical conductivity of the mixed $\mathrm{Ni}-\mathrm{Cu}$ ferrite system from room temperature to well beyond Curie temperature was undertaken. The results of such a study presented in this communication are explained on the basis of the hopping model.

\section{EXPERIMENTAL DETAILS}

Nano ferrite samples with the chemical formula $\mathrm{Ni}_{1-x} \mathrm{Cu}_{x}$ $\mathrm{Fe}_{2} \mathrm{O}_{4}(X=0.0,0.2,0.4,0.5,0.6,0.8$, and 1.0) were synthesized by using citrate gel auto combustion technique. The molar quantity of AR grade of Nickel Nitrate $\left(\mathrm{Ni}\left(\mathrm{NO}_{3}\right)_{2} 6 \mathrm{H}_{2} \mathrm{O}\right)$, Copper Nitrate $\left(\mathrm{Cu}\left(\mathrm{NO}_{3}\right)_{2} 3 \mathrm{H}_{2} \mathrm{O}\right)$, Ferric Nitrate $\left(\mathrm{Fe}\left(\mathrm{NO}_{3}\right)_{2} 9 \mathrm{H}_{2} \mathrm{O}\right)$, Citric Acid-Citrate $\left(\mathrm{C}_{6} \mathrm{H}_{8} \mathrm{O}_{7} \mathrm{H}_{2} \mathrm{O}\right)$ and Ammonia $\left(\mathrm{NH}_{3}\right)$ raw materials were taken as starting material. Metal nitrates and citric acid were dissolved in deionized water. Metal nitrate solutions were mixed with citric acid solution in 1:3 molar ratio of nitrate to citric acid. The $\mathrm{p}^{\mathrm{H}}$ value of the solution was adjusted to 7 using ammonia. The solution was first heated at $80^{\circ} \mathrm{C}$ to transform into gel and then ignited in a self-propagating combustion manner to form a fluffy loose powder. The as-burnt ferrite powders were grained by agate motor then calcined at $700^{\circ} \mathrm{C}$ for $5 \mathrm{hr}$. the calcined ferrite powders were again grained by agate motor. As this method is a chemical route it requires no ball milling hence little scope of contamination, and better homogeneity. The sintered powders were mixed with $2 \%$ of PVA as a binder and uniaxially pressed at a pressure of about $3-5$ tons $\mathrm{cm}^{-2}$ to form pellets of $10 \mathrm{~mm}$ diameter and $2-3 \mathrm{~mm}$ thickness. These pellets were finally sintered at $1050^{\circ} \mathrm{C}$ for $12 \mathrm{~h}$ in a programmable furnace to remove the organic binder.

The structural characterization was carried out using X-Ray Diffractomerter Bruker (Karlsruhe, Germany) D8 advanced system with a diffracted beam monochromatic $\mathrm{Cu}$ $\mathrm{K}_{\alpha}$ radiation $(\lambda=1.5405 \AA)$ radiation source between the Bragg Angles $20^{\circ}$ to $80^{\circ}$ in steps of $0.04^{\circ} / \mathrm{Sec}$. The bulk density $\rho_{m}, \mathrm{X}$-ray density $\rho_{x}$ and porosity $P$ as function of $\mathrm{Cu}$ 
concentrations were estimated as follows. The bulk density, $\rho_{m}$ was determined using formula

$$
\rho_{m}=\frac{m}{\pi r^{2} h}
$$

where $m$ is the mass, $r$ the radius and $h$ the height of the sample.The X-ray density $\rho_{x}$ of the prepared samples was calculated by the relation

$$
\rho_{x}=\frac{8 M}{N a^{3}}
$$

where $M$ is the molecular weight of the samples, $N$ is the Avogadro's number and $a$ is the lattice constant. Each cell has 8 formula units.

The porosity $P$ of the ferrite nanoparticles was then determined using the relation [9]

$$
P=1-\frac{\rho_{m}}{\rho_{x}}
$$

where $\rho_{m}$ and $\rho_{x}$ are the bulk and X-ray densities, respectively.

The DC electrical properties were carried out as a function of composition and temperature by the two probe method [10] from room temperature to well beyond the Curie temperature.

The relationship between resistivity and temperature may be expressed as [11]

$$
\rho=\rho_{o \varepsilon} \Delta \mathrm{E} / k_{B} T
$$

where $\rho$ is the dc electrical resistivity at temperature $T, K_{B}$ the Boltzmann constant and $\Delta E$ the activation energy

\begin{tabular}{|c|c|c|c|c|}
\hline Composition $(x)$ & $\begin{array}{c}\text { Particle } \\
\text { Size (nm) }\end{array}$ & $\begin{array}{c}X \text {-ray } \\
\text { density } \\
\left(\mathrm{gm} / \mathrm{cm}^{3}\right)\end{array}$ & $\begin{array}{c}\text { Bulk } \\
\text { density } \\
\left(\mathrm{gm} / \mathrm{cm}^{3}\right)\end{array}$ & $\begin{array}{c}\text { Porosity } \\
(\%)\end{array}$ \\
\hline 0 & 58.91 & 5.356 & 5.07 & 5.339 \\
\hline 0.2 & 46.3 & 5.396 & 4.976 & 7.782 \\
\hline 0.4 & 49.2 & 5.429 & 4.943 & 8.952 \\
\hline 0.5 & 37.3 & 5.452 & 4.937 & 9.446 \\
\hline 0.6 & 36.9 & 5.48 & 4.892 & 10.730 \\
\hline 0.8 & 43.33 & 5.543 & 4.862 & 12.286 \\
\hline 1 & 36.7 & 5.669 & 4.844 & 14.553 \\
\hline
\end{tabular}
corresponding to the electrical process.

TABLE I: PARTICLE SiZE, X-RAY DENSITY, BUlK DENSITY AND POROSITY WITH COMPOSITION OF MIXED NI-CU NANO FERRITES

\section{RESUlTS AND DisCUSSION}

\section{A. X-Ray Analysis}

The X-ray diffraction patterns for $\mathrm{Ni}_{1-X} \mathrm{Cu}_{X} \mathrm{Fe}_{2} \mathrm{O}_{4}(0 \leq X \leq$ 1) was sintered at $700^{\circ} \mathrm{C}$ are shown in Fig. 1. The $X$-ray patterns show all sample are existence of the single phase of cubic spinel structure [12] with the reflection the samples planes (111), (220), (311), (400), (511) and (440). It can be seen from the table I the values of the particle size varies from $36.7 \mathrm{~nm}$ to $58.91 \mathrm{~nm}$. Though all the samples were prepared under identical condition, the crystallite size was not the same for all $\mathrm{Cu}$ concentrations. This was probably due to the preparation condition followed here which gave rise to different rate of ferrite formation for different concentrations of $\mathrm{Cu}$, favoring the variation of crystallite size. Fig. 2 indicate that the X-ray density $\left(D_{X}\right)$ increases from $5.356 \mathrm{gm} / \mathrm{cm}^{3}$ to $5.669 \mathrm{gm} / \mathrm{cm}^{3}$ and bulk density (D) decreases from 5.07 $\mathrm{gm} / \mathrm{cm}^{3}$ to $4.844 \mathrm{gm} / \mathrm{cm}^{3}$ with the increase in $\mathrm{Cu}$ ion content, this can be attributed to the atomic weight and density of Copper $\left(63.546,8.96 \mathrm{gm} / \mathrm{cm}^{3}\right)$ which are higher than those of nickel $\left(53.933,8.91 \mathrm{gm} / \mathrm{cm}^{3}\right)$.the oxygen ions which diffuse through the material during sintering also accelerate the densification of the material. The X-ray density is higher than the apparent value due to the existence of pores which depends on the sintering condition. Fig. 3 indicates that the porosity increases by $\mathrm{Cu}$ content increase which reflects the similar behavior of X-ray density, it is due to the larger ionic radius of $\mathrm{Cu}(0.73 \AA)$ compared to $\mathrm{Ni}(0.69 \AA)$.

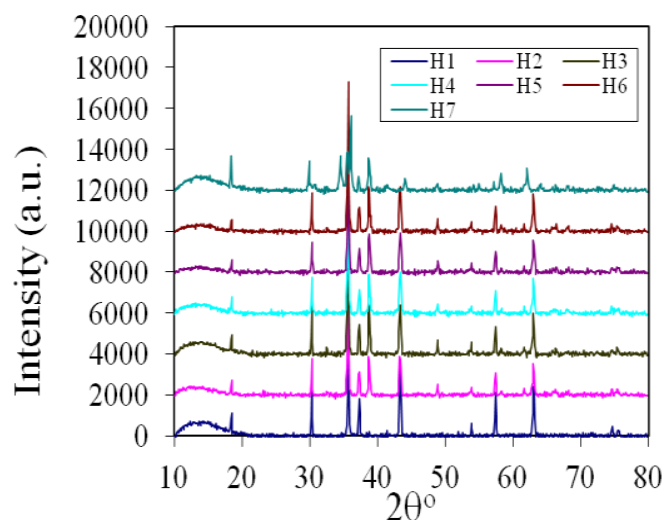

Fig. 1. X-ray diffraction pattern of $\mathrm{Ni}_{1-x} \mathrm{Cu}_{x} \mathrm{Fe}_{2} \mathrm{O}_{4}$ ferrites (where $X=0: \mathrm{H} 1$, 0.2:H2, 0.4:H3, 0.5:H4, 0.6:H5, 0.8:H6 and 1.0:H7).

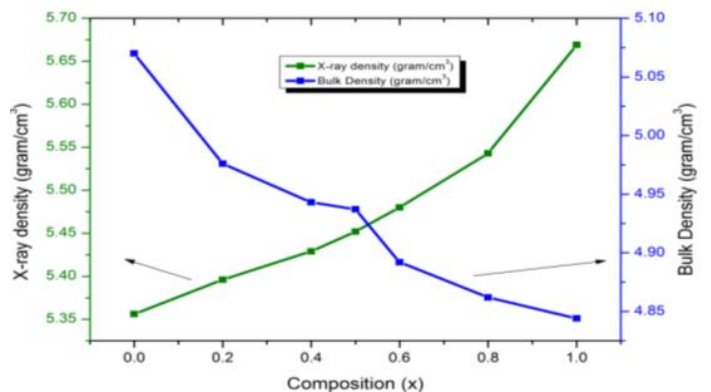

Fig. 2. Variation of X-ray density and Bulk Density with Cu concentration.

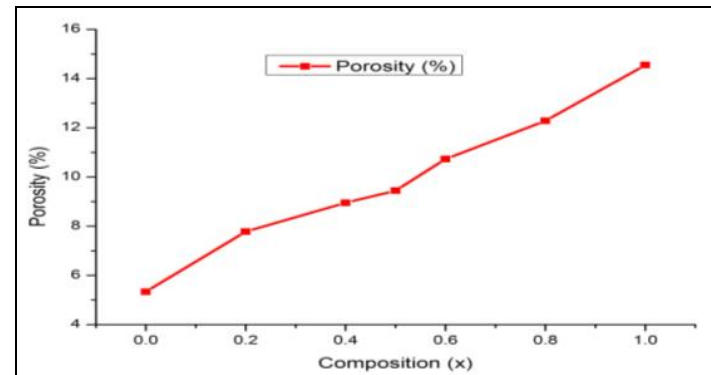

Fig. 3. Variation of Porosity with $\mathrm{Cu}$ concentration electrical properties.

\section{B. Temperature-Dependant of DC Resistivity}

The temperature-dependant of dc resistivity was measured as a function of temperature for all samples from room temperature to well beyond Curie temperature, which is 
described in Fig. 4 follows Arrhenius plot. It showed that the resistivity of the prepared $\mathrm{Ni}-\mathrm{Cu}$ nano ferrite materials decreased with increasing temperature for each sample. This proved the semiconductor nature of synthesized samples [13].

From Fig. 4 the change of slope is attributed to change in conductivity mechanism. The conduction at a lower temperature ( below curie temperature) is due to hopping of electrons [14] between $\mathrm{Fe}^{2+}$ and $\mathrm{Fe}^{3+}$ ions, whereas at a higher temperature (above curie temperature ) due to hopping of polarons [15]-[17].

TABLE II: ELECTRICAL PROPERTIES WITH COMPOSITION OF MIXED NI-CU NANO FERRITES

\begin{tabular}{|cccccc|}
\hline $\begin{array}{c}\text { Sl. } \\
\text { No }\end{array}$ & $\begin{array}{c}\text { Composition } \\
(x)\end{array}$ & $\begin{array}{c}\text { Para } \\
\text { Region } \\
\left(E_{P}\right) \text { ev }\end{array}$ & $\begin{array}{c}\text { Ferro } \\
\text { Region } \\
\left(E_{F}\right) \text { ev }\end{array}$ & $\begin{array}{c}\text { Activation } \\
\text { Energy } \\
(\triangle E) \text { ev }\end{array}$ & $\begin{array}{c}\text { Conductivity } \\
(\sigma)\left(\Omega^{-1}-\mathrm{cm}^{-1}\right) \\
(\text { Room Temp })\end{array}$ \\
\hline 1 & 0 & 0.698 & 0.369 & 0.329 & $8.04 \times 10^{-05}$ \\
2 & 0.2 & 0.717 & 0.402 & 0.315 & $5.28 \times 10^{-04}$ \\
\hline 3 & 0.4 & 0.75 & 0.454 & 0.296 & $6.38 \times 10^{-04}$ \\
4 & 0.5 & 0.788 & 0.502 & 0.286 & $6.74 \times 10^{-04}$ \\
5 & 0.6 & 0.836 & 0.566 & 0.27 & $8.08 \times 10^{-04}$ \\
6 & 0.8 & 0.859 & 0.609 & 0.25 & $2.02 \times 10^{-03}$ \\
7 & 1 & 0.954 & 0.731 & 0.223 & $4.71 \times 10^{-03}$ \\
\hline
\end{tabular}

\section{Composition Dependence of DC Electrical Conductivity}

DC electrical conductivity of the Ni-Cu system was found to increase from $8.04 \times 10^{-05}(\Omega-\mathrm{cm})$ to $4.71 \times 10^{-03}(\Omega-\mathrm{cm})$ at room temperature with the increase in $\mathrm{Cu}$ concentration form 0.0 to 1.0 as given in Table II. This increase in conductivity is due to the fact that $\mathrm{Cu}$ has smaller value of resistivity $\left(1.7 \times 10^{-6} \Omega-\mathrm{cm}\right)$ as compared to that of $\mathrm{Ni}\left(7.0 \times 10^{-6} \Omega-\mathrm{cm}\right)$ [18]. The increase in conductivity may be due to the hopping of electrons between $\mathrm{Fe}^{2+} \leftrightarrow \mathrm{Fe}^{3+}$ on tetrahedral sites that increases the conduction as $\mathrm{Cu}$ is added, which are produced during sintering [13]. The decrease in resistivity may also be due to $\mathrm{Cu}^{2+} \rightarrow \mathrm{Cu}^{+}$transition with the variation of $\mathrm{Cu}$ content in $\mathrm{Ni}-\mathrm{Cu}$ ferrite [19].

\section{Composition Dependence of Activation Energy ( $\Delta E)$}

The activation energies in the ferrimagnetic and para magnetic regions are calculated from the slopes of plots of $\ln (\rho \mathrm{T})$ versus $10^{3} / \mathrm{T}$ and presented in Table II. The activation energy in the paramagnetic region is higher than that in the ferrimagnetic region. The activation energies of prepared samples as determined by the difference between the activation energies in the paramagnetic and ferrimagnetic regions $(\Delta \mathrm{E})$ which is given in column (5) of Table II. The Fig. 6 shows the variation the activation energy in the paramagnetic region, ferrimagnetic region. The value of activation energy of samples decreased from $0.329 \mathrm{eV}$ to $0.223 \mathrm{eV}$ as the $\mathrm{Cu}$ concentration is increased from 0.0 to 1.0. High activation energy goes hand in hand with a low conductivity of the ferrites. Similar result was observed by samokhralov and rustmov [20]. The decrease in activation energy may be attributed to the creation of small number of oxygen vacancies [13]. It may also be justified due to the decrease in resistivity with the increase in $\mathrm{Cu}$ concentration because activation energy behaves in the similar way as that of dc electrical resistivity as reported by others [13], [21]. The decreasing trend of activation energy with the increase in $\mathrm{Cu}$ concentration may also be due to dominant role of $\mathrm{Cu}$ in conductivity.

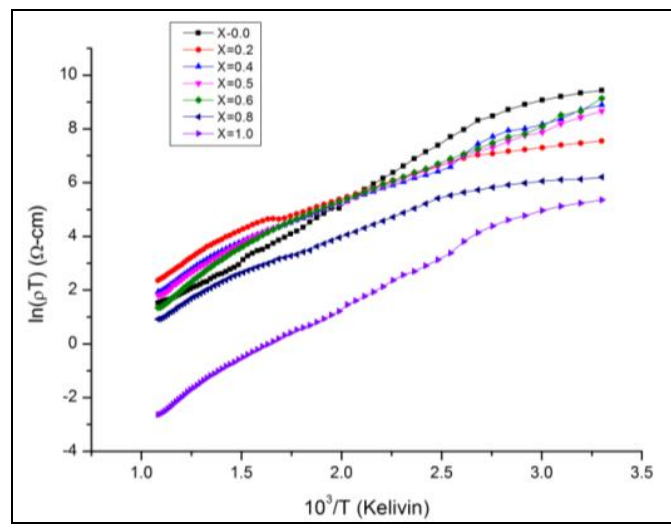

Fig. 4. Variation of DC resistivity with inverse temperature.

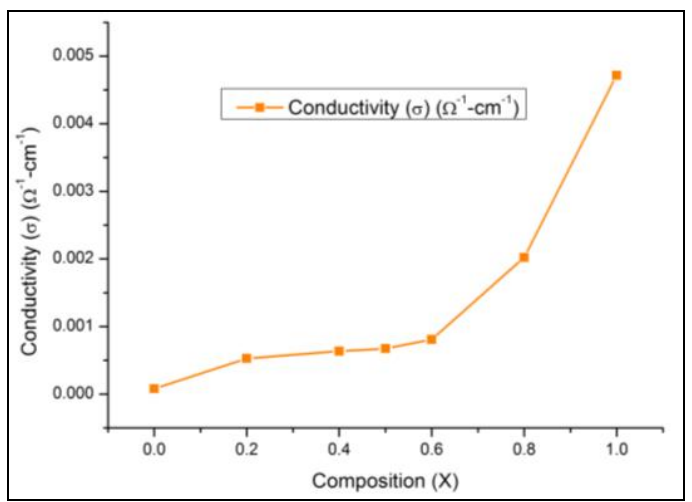

Fig. 5. Variation of electrical conductivity with $\mathrm{Cu}$ concentration.

TABLE III: CURIE TEMPERATURES OF MIXED NI-CU NANO FERRITES

\begin{tabular}{|c|c|c|c|}
\hline \multirow[t]{2}{*}{$\begin{array}{l}\text { Sl. } \\
\text { No. }\end{array}$} & \multirow[t]{2}{*}{ Composition $(x)$} & $d c$ resistivity & $\begin{array}{c}\text { Loria } \\
\text { technique }\end{array}$ \\
\hline & & \multicolumn{2}{|c|}{$\begin{array}{l}\text { Curie temperature } \\
\left(\mathrm{T}_{\mathrm{C}}\right) \text { (Kelvin) }\end{array}$} \\
\hline 1 & 0 & 812.08 & 808 \\
\hline 2 & 0.2 & 738.22 & 736 \\
\hline 3 & 0.4 & 730.19 & 726 \\
\hline 4 & 0.5 & 688.42 & 686 \\
\hline 5 & 0.6 & 676.59 & 674 \\
\hline 6 & 0.8 & 665.42 & 668 \\
\hline 7 & 1 & 646.20 & 648 \\
\hline
\end{tabular}

\section{E. Composition Dependence of Curie Temperature}

From the plots of $\ln (\rho \mathrm{T})$ with reciprocal of temperature as shown in Fig. 4, at particular temperature indicating that sample changing from ferrimagnetism to paramagnetism, this temperature is known as Curie temperature. The Curie temperatures of the samples are presented in the Table III. It is clear the Curie temperature decreases from $812.08 \mathrm{~K}$ to $646.20 \mathrm{~K}^{2} \mathrm{Cu}^{2+}$ composition increasing from $X=0.0$ to 1.0 . These values are good agreement with Curie temperature determined by Loria technique. The Fig.7 Shows that the variation of Curie temperature with composition in $\mathrm{dc}$ resistivity and Loria technique. 


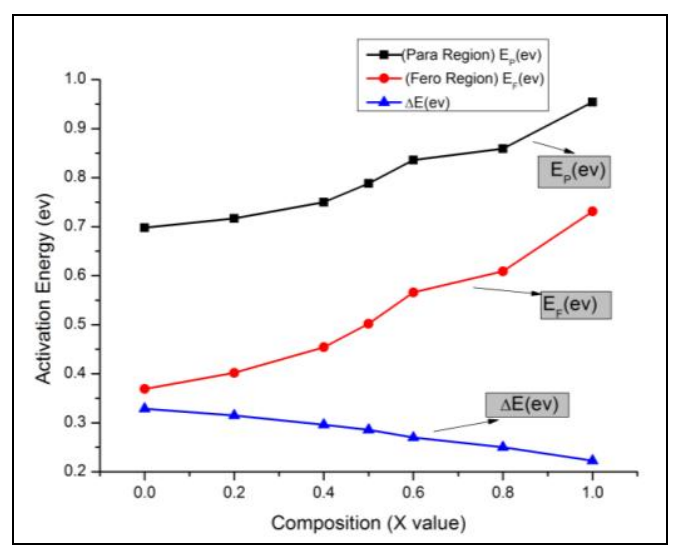

Fig. 6. Variation of para region $\left(\mathrm{E}_{\mathrm{p}}\right)$, fero region $\left(\mathrm{E}_{\mathrm{f}}\right)$ and activation energy $(\Delta \mathrm{E})$ with $\mathrm{Cu}$ concentration.

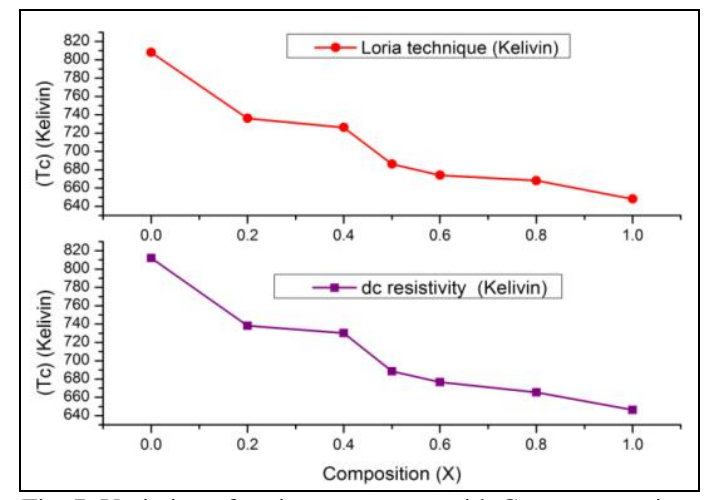

Fig. 7. Variation of curie temperature with $\mathrm{Cu}$ concentration.

\section{CONCLUSION}

The substitution of $\mathrm{Cu}$ in the $\mathrm{Ni}_{1-X} \mathrm{Cu}_{X} \mathrm{Fe}_{2} \mathrm{O}_{4}$ ferrites causes appreciable changes in its structural and electrical properties. All samples have existence of single phase cubic spinel structure with the increase of x-ray density and porosity whereas decrease of bulk density, conductivity and activation energy with increasing $\mathrm{Cu}$ contents. DC electrical resistivity decreases with the increase in temperature which confirms the semiconductor like behavior of the sintered materials. The activation energy in the ferrimagnetic region is in general less than that in the paramagnetic region. The Curie temperature determined from DC electrical properties was found in satisfactory agreement with that determined from Loria technique.

\section{ACKNOWLEDGMENT}

First author K. V. K. is grateful to Dr. M. Thirumala Chary, Principal, Professor \& HOD of Chemistry, JNTUH College of Engineering, Nachupally, Karimnagar, (Dist) for his constant encouragement to carry out this research work. Second author R. S. is grateful to Prof. N. Venkateswarlu, Principal, Vignan's Institute of Technology \& Aeronautical Engineering College, Hyderabad. Third author D.R. is grateful to Prof. T. L. N. Swamy, Principal Nizam College. Forth author R. K. is thankful to Dr. V. S. K. Reddy, Principal MRCET for his encouragement.

\section{REFERENCES}

[1] H. M. El-Sayed, "Effect of induced magnetic anisotropy on the hysteresis parameters of Co ferrite prepared from nano-sized particles," Journal of Alloys and Compounds, vol. 474, no. 1-2, pp. 561-564, 2009.

[2] S. Thakur et al., "Ordering in indium substituted nano-nickel-zinc ferrite," J. Appl. Phys., vol. 105, pp. 07A521.

[3] P. Mathur, A. Thakur, and M. Singh, "Effect of nanoparticles on the magnetic properties of Mn-Zn soft ferrite," JMMM, vol. 320, no. 7, pp. 1364-1369, 2008.

[4] A. Dias, R. L. Moreira et al., "Microstructural dependence of the magnetic properties of sintered NiZn ferrites from hydrothermal powders," JMMM, vol. 172, no. L9-L14, 1997.

[5] K. Roumaiah, "The Transport Properties of the Mixed Ni-Cu Ferrite," Journal of Alloys and Compounds, vol. 465, 2008, pp. 291-295.

[6] S. Krupicka and P. Novak, Oxide spinels Ferroelectric Materials, vol. 3, ed, E P Wohlforth ed., Amstermam: North-Holland0, vol. 3, 1982.

[7] S. A. Patil, S. M. Otari, V. C. Mahajan, M. G. Patil, A. B. Patil, M. K Soudagar, B. L. Patil, and S. R. Sawant, "Structural, IR and Magnetisation Studies on La3+ Sub-stituted Copper Ferrite," Solid State Communication, vol. 78, no. 1, 1991, pp. 39-42.

[8] J. M. Song, J. G. Koh, and J. Magn, Magn. Mater., vol. 152, 1996, pp. 383.

[9] M. J. Iqbal and M. R. Siddiquah, J. Magn. Magn. Mater., vol. 320, no. 845, 2008.

[10] C. B. Kolekar, P. N. Kamble, and S. G. Kulkarni, "Effect of Gd3+ Substitution on Dielectric Behaviour of Copper-Cadmium Ferrites," Journal of Materials Science, vol. 30, no. 22, 1995, pp. 5784-5788.

[11] S. O. Kasap, Principles of Electronic Materials and Devices, New York: McGraw-Hill, 2006.

[12] S. A. Mazen, S. F. Mansour, and H. M. Zaki, "Some physical and magnetic properties of Mg-Zn ferrite," Cryst. Res. Technol., vol. 38, no. 6,471-478, 2003, 15 June 2003.

[13] M. U. Islam, I. Ahmad, T. Abbas, M. A. Chaudhry, R. Nazmeen, "Advanced Materials," in Proc. the 6th International Symposium, 1999, pp. 155.

[14] L. G. V. Uitert, "High-Resistivity Nickel Ferrites-The Effect of Minor Additions of Manganese or Cobalt," Journal of Chemical Physics, vol. 24, no. 2, 1956, pp. 306-310.

[15] M. I. Klinger, "Two-Phase Polaron Model of Conduction in Magnetite-Like Solids," Journal of Physics C: Solid State Physics, vol. 8, no. 21, 1975, pp. 3595.

[16] N. F. Mott and R. W. Gurney, Electronics Process in Ionic Crystals, Oxford: Oxford University Press, 1948.

[17] M. I. Klinger, "Electron conduction in magnetite and ferrites," Physica Status Solidi (B), vol. 79, no. 1, 1977, pp. 9-48.

[18] C. Kittel, An introduction to solid state physics, 7th Ed, New York, London: Wily, 1976, pp. 160.

[19] J. H. Nam, H. H. Jung, J. Y. Shin, and J. H. Oh, IEEE Trans. Magn., vol. 31, 1995, pp. 3985-3987.

[20] A. A. Samokhralov and A. G. Rustmov, Soviet Physics-Solid State, vol. 7, 1965, pp. 961

[21] M. U. Islam, M. A. Chaudhry, T. Abbas, and M. Umar, Mater. Chem. Phys., vol. 48, 1997, pp. 227-229.

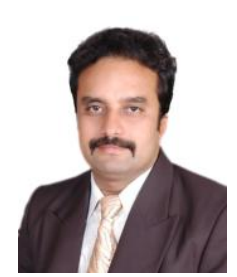

K. Vijaya Kumar is working as an assistant professor in the Department of Physics, JNTU Hyderabad College of Engineering, Nachupally (Kondagattu), Karimnagar-505501, Andhra Pradesh, India. For the credit of his research work, he published 30 research papers in various reputed International journals. He is doing research in the area of materials science. He has 15 years of teaching experience. In recognition to his committed academic activity, he authored 8 books on Engineering Physics and Applied Physics for under graduate students. He received the M.Sc. (Physics with Materials Science) and Ph.D. (Physics with Materials Science) and P.G.Diploma in English Language Teaching degrees from the Osmania University, Hyderabad, India.

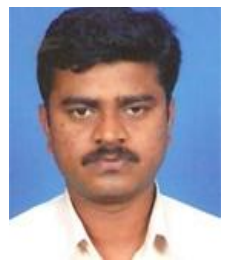

R. Sridhar received the M.Sc. (Physics) degree from the Osmania University, Hyderabad, India in 1998 and Ph.D. pursuing from JNTUH University Hyderabad, India. For the credit of his of his research work, he published three research papers in International Journals, Six research papers presented at International Conferences and National Conferences and has 14 years of teaching experience. His current area of research is on Magnetic and Electrical properties of ferrite nano materials by Citrate-Gel auto combustion method. At present he is working as Associate Professor, Department of Basic Science \& Humanities, Vignan's Institute of 
Technology \& Aeronautical Engineering College, Deshmukhi, Nalgonda-Dist, Andhra Pradesh, India.

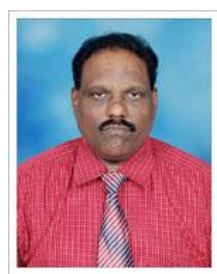

D. Ravinder is working as a professor and the head Department of Physics, Nizam College, Osmania University, Hyderabad, Andhra Pradesh, India. His research work is on magnetic and electrical properties of ferrites, thin films, GMR materials. Cu-Co alloy thin films and nano-materials by pulsed laser deposition, sol-gel, citrate precursor method and electro deposition. To his credit, he has published 150 research papers in International Journals.

He has been awarded young scientist award received by Dr.Abdual Kalam (former President of India), for outstanding contributions in his field of Science and Technology. UGC research award, Boyscast by DST (Department of Science and Technology), Government of India, JSPS fellowship Japan and Royal Society fellowship, UK. He visited USA, UK,
Canada, Sweden, Ireland, Singapore and Japan for collaborative Research and Invited talks.

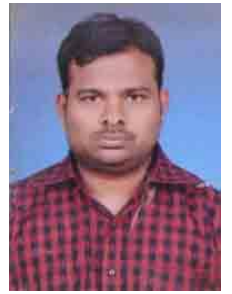

K. Rama Krishna has been working as an asst professor, Department of Physics, Malla Reddy College of Engineering \& Technology, Hyderabad. He did M.Sc in physics from Osmania University, Hyderabad, India, M.Phil from Annamali University, Chidambaram, India. He has submitted his Ph.D thesis in June 2013 to JNTUH University, Hyderabad, India.

He published seven researchp paers in International Journals, Ten research papers presented at International Conferences and National Conferences and has 11 years of teaching experience. His current area of research is on Magnetic and Electrical properties of ferrite nano materials by Citrate-Gel auto combustion method. 